\title{
DIVERSIDADE GENÉTICA, CRESCIMENTO E PRODUÇÃO DE GENÓTIPOS DE BANANEIRA 'PRATA-ANÃ' EM ÁREA COM MAL DO PANAMÁ ${ }^{1}$
}

\author{
OSDNÉIA PEREIRA LOPES ${ }^{2}$, VICTOR MARTINS MAIA ${ }^{3}$, ADELICA APARECIDA XAVIER $^{4}$, \\ MÁRCIA REGINA DA COSTA ${ }^{5}$, MARIA GERALDA VILELA RODRIGUES ${ }^{6}$
}

RESUMO - No perímetro irrigado do Jaíba, no norte de Minas Gerais, existem relatos sobre a presença de alguns genótipos de banana'Prata-Anã' supostamente tolerantes ao mal-do-panamá, nos quais a doença não se estabeleceu após 15 anos de cultivo, mesmo na presença do patógeno. Portanto, objetivou-se avaliar a diversidade genética, o desempenho agronômico e o comportamento dos clones da bananeira'PrataAnã' cultivada em área com histórico do mal-do-panamá. Foram coletados vinte e quatro genótipos, 11 caracterizados no momento da coleta como doentes (GEN 1, GEN 2, GEN 3, GEN 4, GEN 5, GEN 6, GEN 7, GEN 8, GEN 9, GEN 10 e GEN 11) e 13 aparentemente sadios (GEN 12, GEN 13, GEN 14, GEN 15, GEN 16, GEN 17, GEN 18, GEN 19, GEN 20, GEN 21, GEN 22, GEN 23 e GEN 24). Estes materiais foram multiplicados em laboratório de cultura de tecidos e levados para plantio na área experimental. Foram avaliados 24 tratamentos (clones de bananeira 'Prata-Anã'), no delineamento em blocos casualizados, com três repetições, 20 plantas por parcela e as seis centrais consideradas como área útil. Avaliaram-se, além da diversidade genética, comprimento e diâmetro do pseudocaule, número de folhas, massa do cacho, das pencas e do engaço, número de pencas e de frutos, comprimento e perímetro do fruto central da segunda penca, porcentagem de plantas mortas, incidência e severidade do mal-do-panamá. A distância genética média entre os clones foi de 43,5\%, variando de 11,8\% a 85\%. Os indivíduos GEN 12, GEN 13, GEN 19 e GEN 22 apresentam maiores diâmetros do pseudocaule ao nível do solo e a $30 \mathrm{~cm}$, e foram mais altos. Os indivíduos GEN 13, GEN 17 e GEN 19 destacaram-se, nos dois ciclos de produção, como tolerantes ao mal-do-panamá. Termos para indexação: Musa spp.,caracteres agronômicos, Fusarium oxysporum f. sp. Cubense.

\section{GENETIC DIVERSITY, GROWTH AND PRODUCTION OF GENOTYPES OF BANANA 'PRATA-ANÃ' IN AREA WITH PANAMA DISEASE}

\begin{abstract}
In the irrigated area of Jaíba in Northern Minas Gerais, there are reports on the presence of some genotypes of banana cv. Prata-Anã supposedly tolerant to the Panama disease, where the disease was not established after 15 years of cultivation even in the presence of the pathogen. Therefore this study aimed to evaluate the genetic diversity, agronomic performance and behavior of genotypes of banana 'Prata-Anã' cultivated in area with a history of Panama disease. Twenty-four families were collected, 11 classified in the moment of the collection as diseased (GEN 1, GEN 2, GEN 3, GEN 4, GEN 5, GEN 6, GEN 7, GEN 8, GEN 9, GEN 10 and GEN 11), and 13 apparently healthy (GEN 12, GEN 13, GEN 14, GEN 15, GEN 16, GEN 17, GEN 18, GEN 19, GEN 20, GEN 21, GEN 22, GEN 23 and GEN 24). This material were multiplied in tissue culture laboratory and taken to planting at the experimental area. Twenty-four treatments were evaluated (clones of banana 'Prata-Anã'), in a randomized block design with three replications, 20 plants per plot and the central six in useful area. In addition to the genetic diversity, length and diameter of pseudostem, leaf number, bunch, hands and rachis weight, number of hands and fruits, length and girth of the central fruit of the second hand, the percentage of dead plants, incidence and severity of Panama disease were evaluated. The average genetic distance between clones was $43.5 \%$, ranging from $11.8 \%$ to $85 \%$. Individuals GEN 12, GEN 13, GEN 19 and GEN 22 showed larger pseudostem at ground level and at $30 \mathrm{~cm}$ above the ground, and were higher. Individuals GEN 13, GEN 17 and GEN 19 stood out in both production cycles as Panama disease tolerant.
\end{abstract}

Index terms: Musa spp., agronomic characters, Fusarium oxysporum f. sp. Cubense.

\footnotetext{
${ }^{1}$ (Trabalho 368-13). Recebido em: 02-10-2013. Aceito para publicação em: 12-06-2014.

${ }^{2}$ Eng. Agrônoma, Doutoranda em Fitotecnia, Universidade Federal de Viçosa, Viçosa-MG. E-mail: neialopesp@ibest.com.br ${ }^{3}$ Eng. Agrônomo, D.Sc., Prof. Universidade Estadual de Montes Claros, Janaúba-MG. E-mail: victor.maia@unimontes.br ${ }^{4}$ Eng. Agrônoma, D.Sc., Prof. Universidade Estadual de Montes Claros, Janaúba-MG. E-mail: adelica@unimontes.br ${ }^{5}$ Eng. Agrônoma, D.Sc., Prof. Universidade Estadual de Montes Claros, Janaúba-MG. E-mail: marcia.costa@unimontes.br ${ }^{6}$ Eng. Agrônoma, D. Sc., Pesq. EPAMIG/URENM, Bolsista FAPEMIG, Nova Porteirinha-MG. E-mail: magevr@epamig.br
} 


\section{INTRODUÇ̃̃O}

O mal-do-panamá, causado pelo fungo Fusarium oxysporum f. sp. cubense, tem grande importância para o cultivo da banana. As plantas infectadas por este patógeno exibem externamente um amarelecimento progressivo das folhas mais velhas para as mais novas, com posterior murcha, seca e quebra junto ao pseudocaule, deixando a planta com aparência de um guarda-chuva fechado. Internamente, nos feixes da bainha do pseudocaule, observam-se pontuações pardoavermelhadas, resultantes da ação do patógeno nos vasos (CORDEIRO, 2005).

No perímetro irrigado do Jaíba, latitude: $15^{\circ} 20^{\prime} 14^{\prime \prime}$ sul e longitude: $43^{\circ} 41^{\prime} 9$ ' ' oeste com 475 metros de altitude, situada no norte de Minas Gerais, onde $90 \%$ da área plantada com bananeira corresponde à variedade 'Prata-Anã', classificada por Ventura e Hinz (2002) como suscetível à raça 1 de $F$. oxysporum f. sp. cubense. Esta doença tem sido relatada com frequência e, muitas vezes, tem inviabilizado o plantio desta variedade. Nos solos arenosos do perímetro irrigado do Jaíba, especialmente na gleba $\mathrm{C} 2$ inaugurada na primeira etapa do projeto (Figura 1), o cultivo da banana'Prata-Anã' não é mais realizado em função da doença, que impede, às vezes, a produção já do primeiro ciclo. No entanto, no mesmo perímetro, há registro de uma área implantada com 'PrataAnã' onde a doença não se estabeleceu após 15 anos de cultivo, mesmo na presença do patógeno. Não se sabe se a supressão desta doença ocorre em função da menor agressividade do inóculo, se as plantas estão em uma área com solo supressivo, que corresponde ao fenômeno de alguns solos prevenirem naturalmente o estabelecimento de patógenos ou inibirem suas atividades patogênicas, sendo portanto os opostos dos solos condutivos, ou, ainda, se o material estabelecido nesta área é um variante de 'Prata-Anã' com alguma resistência ou tolerância a $F$. oxysporum f. sp. cubense. Na região, há alta heterogeneidade de materiais plantados e com identificações muitas vezes divergentes.

Alguns trabalhos demonstram a eficiência da utilização de marcadores RAPD (Random Amplified Polymorphic DNA) na separação das cultivares que são derivadas a partir de diferentes grupos genômicos e em variantes somaclonais de bananeira (VISSER, 2000; GUBBUK et al., 2004). Esse marcador molecular é interessante pela facilidade de execução, número de polimorfismos gerados, baixo custo das análises e, principalmente, por permitirem a análise de genomas desconhecidos (FERREIRA;
GRATAPAGLIA, 1996).

Diante da diferenciação de algumas plantas em apresentar tolerância ao mal-do- panamá em área que apresente alta incidência da doença, objetivou-se verificar se estas plantas são distintas geneticamente daquelas que desenvolveram a doença, estimar a variabilidade genética existente entre elas por meio de marcadores moleculares do tipo RAPD, bem como avaliar o desempenho agronômico e seu comportamento sob cultivo em área infestada com o patógeno para identificar algum genótipo com tolerância à doença.

\section{MATERIAIS E MÉTODOS}

Em uma área de aproximadamente um hectare de bananal da variedade Prata-Anã, situada na propriedade comercial Luiz Schwartz, localizada no perímetro irrigado do Jaíba, no município de Matias Cardoso-MG, que possui as seguintes coordenadas geográficas: S $15^{\circ} 04^{\prime} 20^{\prime \prime}$ e WO $43^{\circ} 47^{\prime} 44^{\prime \prime}$ e altitude de $463 \mathrm{~m}$, com histórico da ocorrência do mal-dopanamá, foram avaliados vinte e quatro genótipos de bananeira. Realizou-se um corte transversal no pseudocaule de plantas já bem formadas para a observação da presença de colonização do fungo resultando em sintomas típicos da doença (escurecimento vascular). Dos 24 genótipos selecionados, 11 foram caracterizados no momento da coleta como doentes, sendo denominadas de (GEN 1, GEN 2, GEN 3, GEN 4, GEN 5, GEN 6, GEN 7, GEN 8, GEN 9, GEN 10 e GEN 11), e 13 aparentemente sadios (GEN 12, GEN 13, GEN 14, GEN 15, GEN 16, GEN 17, GEN 18, GEN 19, GEN 20, GEN 21, GEN 22, GEN 23 e GEN 24).

Destas plantas, obtiveram-se explantes a partir dos rizomas de cada genótipo, sendo levados ao laboratório de micropropagação da Universidade Estadual de Montes Claros - Câmpus de Janaúba para obtenção dos clones sadios de cada família. Após a obtenção dos clones, foi realizada a remoção de folhas jovens para a realização da análise de divergência genética.

O DNA genômico foi extraído seguindo a metodologia de Doyle e Doyle (1990) a partir de 200 $\mathrm{mg}$ de folhas frescas. Para a verificação da qualidade do DNA, utilizou-se de um minigel de agarose a $0,8 \%$, que foi corado em solução de brometo de etídeo $\left(0,5 \mathrm{mg} \mathrm{L}^{-1}\right)$. O DNA foi quantificado em espectrofotômetro, realizando-se leituras na absorbância de luz UV 260 e $280 \mathrm{~nm}$. A partir daí, realizou-se a diluição mantendo as amostras com 10 ng de DNA.

As reações de amplificação RAPD foram 
realizadas com as seguintes concentrações finais: DNA genômico (30 ng), tampão $10 \mathrm{X}$ Tris- $\mathrm{HCl} / \mathrm{KCl}$ (10 mM/50 mM), $\operatorname{MgCl}_{2}(2,8 \mathrm{mM})$, dNTPs $(0,1 \mathrm{mM}$ de cada), primer ( 5 pmol), Taq DNA polimerase (1 unidade) e água ultrapura para completar $25 \mu \mathrm{L}$. As amplificações foram efetuadas sob as seguintes condições: um ciclo a $94{ }^{\circ} \mathrm{C}$ por 3 minutos; 40 ciclos de $94{ }^{\circ} \mathrm{C} / 15$ segundos, $35^{\circ} \mathrm{C} / 30$ segundos e $72{ }^{\circ} \mathrm{C} / 1$ minuto; ao final desses, um ciclo a $72{ }^{\circ} \mathrm{C}$ por 7 minutos e, logo após, reduziu-se a temperatura para $4{ }^{\circ} \mathrm{C}$. Os produtos resultantes das amplificações foram separados por eletroforese em gel de agarose a $1,5 \%$, a $5 \mathrm{~V} \mathrm{~cm}^{-1}$, em tampão TBE $1 \mathrm{X}$ por três horas e corados em solução de brometo de etídeo a $0,5 \mathrm{mg}$ $\mathrm{L}^{-1}$. Visualizaram-se os fragmentos amplificados sob luz ultravioleta e fotografados em sistema digital de Fotodocumentação UVP® Life Science software.

Utilizaram-se primers do KIT OPERON tomados ao acaso: OPC-07, OPL-03, OPE-05, OPA06, OPA-10, OPF-10, OPH-14, OPP-14, OPR-11, OPB-13, OPO-10 e OPM-08. Uma matriz binária de dados foi obtida a partir da leitura dos géis, atribuindo-se valor igual a 1 , se banda homóloga estiver presente, e 0 , caso contrário, para o cálculo do coeficiente de similaridade ( $\mathrm{S} i j)$ de Jaccard entre pares de genótipos. A partir desses valores, foi realizada uma análise de cluster (agrupamento) pelo método não ponderado de agrupamento de pares (UPGMA), utilizando a média aritmética, cujo resultado pode ser visualizado na forma gráfica de um dendrograma. Os cálculos de similaridade e construção do dendrograma foram efetuados com auxílio do programa computacional GENES (CRUZ, 2006).

As plantas obtidas de cada genótipo permaneceram em casa de vegetação durante três meses para aclimatação e, em seguida, foram levadas para o plantio no campo, na propriedade comercial Luiz Schwartz, localizada no perímetro irrigado do Jaíba, no município de Matias Cardoso-MG, que possui as seguintes coordenadas geográficas: $\mathrm{S} 15^{\circ}$ 04' 20" e WO 43 47' 44" e altitude de $463 \mathrm{~m}$.

$\mathrm{Na}$ área onde foi montado o experimento, havia sido plantada, anteriormente, bananeira-'PrataAnã', que foi altamente atacada pelo Fusarium oxysporum f.sp. cubense, sendo necessária a eliminação deste bananal. Foi realizada a abertura dos sulcos, sendo os genótipos plantados no espaçamento de 4,0 $\mathrm{m} \mathrm{x} \mathrm{2,0} \mathrm{m} \times 1,7 \mathrm{~m}$.

O manejo adotado foi todo realizado de acordo com a rotina e as recomendações da propriedade comercial Luiz Schwartz. O sistema de irrigação utilizado foi a microaspersão, com irrigações realizadas diariamente, de acordo com os dados de evapotranspiração coletados na EPAMIG - Mocambinho-MG, sendo assim calculada a lâmina de irrigação diária. Não foi realizado controle fitossanitário.

O delineamento experimental foi o em blocos casualizados, no esquema fatorial $24 \mathrm{x}$ 5 , sendo 24 tratamentos referentes aos clones de bananeira-'Prata-Anã' e cinco épocas de avaliação $(65 ; 100 ; 150 ; 210$ e 270 dias após o plantio) das características de crescimento. Os componentes da produção, porcentagem de plantas mortas, incidência e severidade do mal- do-panamá, foram avaliados apenas na data da colheita. Foram utilizadas três repetições com 20 plantas por parcela, sendo as seis plantas centrais úteis da parcela.

No primeiro ciclo de produção, foram realizadas as avaliações de crescimento das plantas. A altura do pseudocaule foi mensurada utilizando-se de fita métrica graduada em centímetros, medindose a distância entre o solo até o ponto de inserção da terceira folha mais nova. Para o diâmetro do pseudocaule ao nível do solo e a $30 \mathrm{~cm}$, mediuse a circunferência ou perímetro do pseudocaule, utilizando-se de uma fita métrica graduada em centímetros e este valor foi dividido por $\pi(3,1415)$ para se obter o diâmetro. O número de folhas foi obtida a partir da contagem direta de folhas totalmente abertas.

Após a última avaliação (270 dias), ocorreram altas porcentagens de plantas mortas, sendo interrompidas as avaliações de crescimento.

A produção das plantas foi avaliada nos dois primeiros ciclos de produção. A massa do cacho, massa das pencas e massa do engaço foram determinadas com o auxílio de uma balança e expressos em quilogramas. A massa do cacho constituiu-se das massas das pencas mais a massa do engaço; a massa das pencas, do somatório das massas de todas as pencas, enquanto o engaço foi pesado isoladamente. Foram feitas contagens diretas do número de pencas e do número de frutos de cada penca. O comprimento e o diâmetro do fruto central da segunda penca foram mensurados com o auxílio de uma fita métrica, sendo que, para o diâmetro, o perímetro foi dividido por $\pi(3,1415)$.

Para o cálculo da porcentagem de plantas mortas, foi realizada a contagem das plantas que morreram com sintomas do mal-do-panamá em relação ao total de plantas expresso em porcentagem. A incidência do mal-do-panamá foi quantificada por contagem das plantas com sintomas da doença. A severidade do mal-do-panamá foi realizada após a colheita do cacho por meio da escala de notas do INIBAP descrita por Carlier (2003) e modificada 
neste trabalho pela adição da nota 7. Atribuiu-se esta nota às plantas que apresentaram todo o tecido vascular com escurecimento pardo-avermelhado, rachaduras no pseudocaule e maioria das folhas secas e quebradas junto ao pseudocaule (aspecto de um quarda-chuva fechado) e sem formação de cacho. A escala de notas de severidade pode ser observada na Tabela 1 .

Os dados foram submetidos à análise de variância e, quando significativos, submetidos aos testes estatísticos. Para o estudo dos genótipos, utilizou do teste de Scott-Knott ao nível de 5\% de probabilidade e, para o estudo de épocas, ajustaramse modelos de regressão. Para a escolha do modelo de regressão, verificou-se a capacidade do mesmo em explicar o fenômeno biológico, a significância dos parâmetros da regressão até nível de $10 \%$ de significância pelo teste $\mathrm{t}$ e o valor do coeficiente de determinação do modelo. A análise estatística foi feita com auxílio do Sistema de Análises Estatísticas e Genéticas V. 5.0 (SAEG, 1997). Utilizou-se da análise descritiva para as características massa do cacho, massa das pencas, massa do engaço, número de pencas, número de frutos, comprimento e diâmetro do fruto, porcentagem de plantas mortas, incidência e severidade do mal-do- Panamá. A escolha da estatística descritiva para as características componentes da produção ocorreu em função do elevado número de plantas mortas e que, portanto, não produziram. Foi realizada também correlação de Pearson entre a porcentagem de plantas mortas e as características de crescimento vegetativo observadas na última data de avaliação.

\section{RESULTADOS E DISCUSSÃO}

A partir da amplificação dos 12 primers utilizados, 11 deles geraram bandas polimórficas, totalizando 82 bandas, sendo 27 polimórficas (33\%) e 55 monomórficas (67\%). Rodrigues et al. (2012) identificaram variabilidade genética entre clones de bananeira-'Prata-Anã' por meio de marcadores RAPD e encontraram porcentagem de bandas polimórficas $(34 \%)$ similar à deste trabalho.

As distâncias genéticas variaram de 11,8 a $85,0 \%$. A maior distância (85\%) foi observada entre os genótipos GEN 5 e GEN 20; e a menor (11,8\%), entre os genótipos GEN 4 e GEN 19. A distância genética média foi de 43,5\% . Como todos os genótipos avaliados são da 'Prata-Anã', sugere-se, com a obtenção dessas distâncias, serem variantes somaclonais. Outros autores em caracterização de clones de bananeira também encontraram distâncias genéticas altas entre os genótipos avaliados, o que demonstra a existência de variações somaclonais (LIBRELON et al., 2013; RODRIGUES et al., 2012; GUBBUK et al., 2004). Em bananeira, ocorrem variações somaclonais em nível muito superior ao que se observa na maioria das outras culturas (provavelmente, devidas à instabilidade mitótica), principalmente em cultura de tecidos, que são também observadas no campo (SILVA et al., 2002), revelando então essa alta variabilidade genética entre elas.

De posse do dendrograma (Figura 2) e da distância média relativa $(43,5 \%)$, foi determinado um ponto de corte que permitiu a formação de oito grupos distribuídos da seguinte forma: Grupo 1 (genótipos GEN 22, GEN 24, GEN 6, GEN 4 e GEN 15 ), Grupo 2 (GEN 10, GEN 18, GEN 8 e GEN 17), Grupo 3 (GEN 20 e GEN 23), Grupo 4 (GEN 12, GEN 19, GEN 3 e GEN 9), Grupo 5 (GEN 16 e GEN 21), Grupo 6 (GEN 1 e GEN 13), Grupo 7 (GEN 7 e GEN 11) e Grupo 8 (GEN 2, GEN 14 e GEN 5). Como os genótipos foram inicialmente separados e identificados pela presença ou ausência de sintomas do mal- do-panamá, ou seja, percebe-se que os genótipos não se agruparam de acordo com a presença ou ausência de sintomas da doença, como foram inicialmente separados e identificados. Este fato é explicado pela característica de o marcador RAPD acessar regiões aleatórias do genoma ideal para detectar diferenças genéticas.

Não houve diferença significativa entre os genótipos quanto ao número de folhas, cuja média geral foi de 10,28 folhas por planta. Não foi observado efeito significativo da interação entre genótipos e épocas de avaliação sobre o diâmetro do pseudocaule ao nível do solo (DPNS) e a $30 \mathrm{~cm}$ do solo (DP30), e altura de planta (AP). Houve efeito significativo sobre estas características apenas de cada fator estudado isoladamente.

$\mathrm{Na}$ Tabela 2, estão apresentadas as médias das variáveis de crescimento, diâmetro do pseudocaule ao nível do solo (DPNS) e a $30 \mathrm{~cm}$ do solo (DP30), bem como da altura de planta (AP) aos 270 dias após o plantio, de 24 clones da cv. Prata-Anã, comparadas pelo teste de Scott-Knott, a 5\% de probabilidade.

Em relação ao diâmetro do pseudocaule ao nível do solo (DPNS), destacaram-se os genótipos GEN 22, GEN 19, GEN 12, GEN 13, GEN 2, GEN 18, GEN 11, GEN 3 e GEN 6, com maiores médias, que formaram um grupo diferente dos demais genótipos. As maiores médias para diâmetro do pseudocaule a $30 \mathrm{~cm}$ do nível do solo (DP30) foram apresentadas pelos genótipos GEN 22, GEN 19, GEN 13, GEN 12 e GEN 18, que formaram o primeiro grupo. Os genótipos GEN 1, GEN 19, GEN 
22, GEN 24, GEN 12, GEN 18, GEN 13 e GEN 23 apresentaram as maiores médias de altura de plantas (AP) quando comparadas com os demais genótipos.

De acordo com Guimarães et al. (2014), existe alta correlação entre o diâmetro do pseudocaule ao nível do solo de bananeira-'Prata-Anã' no momento do florescimento e o peso do cacho, sendo este um bom indicador de vigor e produção da planta.

Assim, pode-se inferir que os genótipos GEN 12, GEN 13, GEN 18, GEN 19 e GEN 22 foram os que se destacaram em todas as variáveis de crescimento avaliadas, sendo, portanto, os mais vigorosos. A média geral de crescimento observada neste experimento foi baixa, pois a última avaliação foi realizada aos 270 dias, uma vez que, após este período, ocorreram altas porcentagens de plantas mortas, impossibilitando determinar o maior potencial de crescimento dos indivíduos que sobreviveram e que, a partir dessa época, iniciaram a floração.

Na Figura 3, estão apresentadas as características de crescimento em função dos dias após o plantio, onde se observou aumento linear, exceto para o diâmetro do pseudocaule a $30 \mathrm{~cm}$ do solo, que apresentou comportamento quadrático. $\mathrm{O}$ diâmetro do pseudocaule ao nível do solo aumentou com o passar dos dias após o plantio, atingindo, na ultima época de avaliação (aos 270 dias), 45,02 $\mathrm{cm}$. Houve incremento na altura de plantas e no número de folhas e, na última época de avaliação, observaram-se plantas com alturas médias de 163,73 cm e 12,11 folhas. Gonçalves et al. (2008) salientam que a altura de planta é uma das principais variáveis sob o ponto de vista fitotécnico e de melhoramento, estando ligada aos aspectos de densidade de plantio, produção e manejo da cultura.

O incremento no diâmetro do pseudocaule, tanto ao nível de solo quanto a $30 \mathrm{~cm}$ durante o crescimento da planta, é esperado, uma vez que está diretamente ligado ao desenvolvimento do indivíduo. A baixa produção, às vezes, pode ser justificada pelo alto índice de quebramento do pseudocaule, fato este atribuído à excessiva altura e à menor espessura do diâmetro (MENDONÇA et al., 2013).

Marques et al. (2011), ao avaliarem as características agronômicas de bananeiras- 'PrataAnã' em três ciclos de produção sob diferentes sistemas de irrigação, obtiveram, na época do florescimento do primeiro ciclo, diâmetro médio a $30 \mathrm{~cm}$, de $20,38 \mathrm{~cm}$; no segundo ciclo foi de 30,89 $\mathrm{cm}$, e no terceiro ciclo de $33,72 \mathrm{~cm}$. Percebe-se, pelos resultados do presente trabalho, que esta é uma característica varietal, que também sofre influência do ambiente e do manejo. Diferentes trabalhos relacionados às características vegetativas e reprodutivas em bananeira relatam correlação significativa entre o perímetro do pseudocaule e a produção do cacho (DONATO et al., 2006; ARANTES et al., 2010; RAHMAN; BALA, 2010 ; GUIMARÃES et al., 2014).

Foi realizada análise de variância para os dados de crescimento, comparando os genótipos apenas na última data de avaliação (270 dias após o plantio). Nesta análise, não foi observada diferença significativa entre os genótipos para o diâmetro do pseudocaule ao nível do solo, diâmetro do pseudocaule a $30 \mathrm{~cm}$ do solo, altura de plantas e número de folhas. Os valores médios destas variáveis, nessa data, foram $45,02 \mathrm{~cm}, 37,57 \mathrm{~cm}$, $163,74 \mathrm{~cm}$ e 12,11, respectivamente.

No primeiro ciclo de produção, todos os genótipos apresentaram mais de $66 \%$ de plantas mortas, destacando-se os genótipos GEN 2, GEN 3, GEN 4, GEN 8, GEN 22 e GEN 24, que apresentaram $100 \%$ de mortalidade. Os genótipos GEN 7, GEN 15, GEN 18 e GEN 21 com menor mortalidade, o valor variou de 66,66 a $77,77 \%$ das plantas mortas (Tabela 3).

Houve incidência do mal-do-panamá em todos os genótipos, dentre os quais o GEN 7, 15, 18 e 21 foram os que apresentaram menores valores, que variaram de 84 a 94\%. Os demais genótipos apresentaram $100 \%$ de incidência da doença. Foram observadas notas de severidade do mal-do-Panamá acima de 2,5, de acordo com a Escala do INIBAP (CHARLIER ;ESCALANT, 2003), para todos os genótipos. Nos genótipos GEN 7, GEN 15, GEN 17 e GEN 19, foi observada menor severidade, cujas notas variaram de 2,66 a 3, 66 .

Observou-se nos genótipos GEN 2, GEN 4, GEN 8, GEN 22 e GEN 24 severidade da doença maior que a descrita na Escala de Severidade utilizada (Tabela 1), o que levou ao uso de nota diferenciada. Para estas plantas, atribuiu-se a nota 7, que caracterizou as plantas que apresentaram folhas murchas, secas e quebradas (com aspecto de "guarda-chuva fechado") ainda aderidas à planta, com rachaduras na base do pseudocaule e presença de coloração intensa pardo-avermelhada no pseudocaule, ausência de cacho e morte da planta.

Os genótipos que apresentaram 100\% de plantas mortas no primeiro ciclo, aos quais foram atribuídas nota 7 de severidade, são compostos por plantas provenientes de cultivo de tecido originalmente obtidas de famílias diagnosticadas como doentes (GEN 2, GEN 4 e GEN 8) no campo; entretanto, os genótipos GEN 22 e GEN 24, que também apresentaram 100\% de mortalidade, tinham 
sido classificados, no início, como sadios.

No segundo ciclo de produção, todos os genótipos apresentaram mais de $70 \%$ de plantas mortas, destacando-se os genótipos GEN 5, GEN 6, GEN 8, GEN 9, GEN 11, GEN 14, GEN 16, GEN 20, GEN 22, GEN 23 e GEN 24, com 100\% de mortalidade. Houve, portanto, aumento do número de genótipos com $100 \%$ de mortalidade em relação ao primeiro ciclo de produção, o que é característico da forma de evolução da doença. Os genótipos GEN 1, GEN 2, GEN 7 e GEN 17 apresentaram menor porcentagem de plantas mortas, variando de 72,21 a 77,77\% (Tabela 4).

Os genótipos que apresentaram 100\% de plantas mortas no segundo ciclo, aos quais foram atribuídas nota 7 de severidade, são oriundos de plantas diagnosticadas no momento da coleta, como doentes (GEN 5, GEN 6, GEN 8, GEN 9 e GEN 11) e como sadias (GEN 14, GEN 16, GEN 20, GEN 22, GEN 23 e GEN 24).

A incidência do mal-do-panamá ocorreu em $100 \%$ dos indivíduos, e foram atribuídas notas de severidade acima de 2 para todos os genótipos. Foram observadas nos genótipos GEN 1, GEN 2, GEN 7, GEN 18 e GEN 19 menores notas de severidade. Os genótipos GEN 5, GEN 6, GEN 8, GEN 9, GEN 11, GEN 14, GEN 16, GEN 20, GEN 22, GEN 23 e GEN 24 apresentaram severidade máxima do maldo-panamá, atribuída conforme escala adotada neste trabalho (Tabela 1).

As chances de infecção de plantas por patógenos radiculares relacionam-se à densidade de inóculo disponível, sendo que, quanto maior a densidade, maiores são as chances de que ocorra a doença e em maior severidade (MICHEREFF et al., 2005). Apesar de na área do perímetro irrigado do Jaíba, onde foram coletados os genótipos, alguns não terem manifestado sintomas visuais da doença, neste experimento, todas as plantas apresentaram sintomas do mal-do-panamá.

$\mathrm{Na}$ área de coleta dos genótipos, em função do não estabelecimento da doença, foi retirado material propagativo para implantação de outros bananais, por considerar-se que o fator envolvido fosse genético. Segundo Cordeiro et al. (2004), a busca desordenada de materiais de bananeira a partir de germoplasma natural selecionado pelo homem pode levar a enganos e, no caso de resistência a patógeno do solo, corre-se o risco de selecionar materiais que possam ter escapado da infecção pela distribuição desuniforme de inóculo dentro da área, dentre outras possibilidades. Em alguns casos, a evolução do mal-do-panamá é rápida, atingindo todas as plantas, e, em outros, isto não acontece. Ventura e Hinz (2002) ressaltam que bananais implantados em solos supressivos à doença leva de 10-15 anos até causar problemas, enquanto em solos condutivos isso ocorre em poucos anos.

Gomes (2010), ao trabalhar com os genótipos retirados da mesma área em que retirou o material para o presente trabalho, em casa de vegetação, e com inoculação controlada, observou que todos os genótipos apresentaram suscetibilidade ao mal-dopanamá. Além disso, quando estes foram plantados em solo coletado da rizosfera das famílias de origem, a resposta foi idêntica. De acordo com este autor, a supressão ao mal-do-panamá da área de origem dos genótipos, possivelmente, está associada às condições presentes no solo, ou que o material pudesse apresentar tolerância a infecção de Fusarium Oxysporum f.sp. Cubense. Na Tabela 5, estão apresentados os dados dos componentes da produção do primeiro ciclo. Foram consideradas somente as plantas que sobreviveram e produziram. O número final de plantas avaliadas quanto aos caracteres produtivos encontra-se descrito nesta tabela.

Foi utilizada análise descritiva dos dados, uma vez que a maioria dos indivíduos de cada genótipo estudado, tanto no primeiro quanto no segundo ciclo, não sobreviveram, inviabilizando a repetição exigida para análise estatística. Portanto, estão apresentados apenas as médias e os desviospadrão do total de indivíduos sobreviventes de cada genótipo, independentemente da distribuição dos blocos na área experimental.

O genótipo GEN 19 destacou-se, produzindo cachos de $20 \mathrm{~kg}$, enquanto os demais apresentaram média geral de $11,34 \mathrm{~kg}$. Médias superiores são relatadas por Donato et al. (2006), Silva et al. (2008) e Donato et al. (2009), que obtiveram cachos de bananeira-'Prata-Anã' de 14,0 a 21,3 kg. Esses cachos menores, observados no presente trabalho, provavelmente ocorreram em função da presença do mal-do-panamá nas plantas avaliadas.

A média geral da massa do engaço (ME) obtida foi de $1,97 \mathrm{~kg}$. Os genótipos que apresentaram menor massa do engaço foram GEN 5, GEN 6, GEN 10, GEN 11 e GEN 19, cujos valores variam entre 0,8 e $1,1 \mathrm{~kg}$. As maiores médias foram encontradas nos genótipos GEN 7, GEN 12, GEN 13, GEN 15, GEN 16, GEN 20 e GEN 21, que ficaram com valores entre 2,4 e $2,9 \mathrm{~kg}$.

Os cachos apresentaram massa média de pencas (cacho sem o engaço) de 9,51 kg, destacandose o genótipo GEN 19, que apresentou maior massa de pencas $(18,9 \mathrm{~kg})$. Não houve grandes diferenças entre os números de pencas (NP) dos diferentes genótipos, cuja média geral foi de 7,89 pencas 
por cacho. O fruto central da segunda penca (CF) apresentou comprimento médio de $11,47 \mathrm{~cm}$ e perímetro de $3,05 \mathrm{~cm}$. Os genótipos GEN 1, GEN 5 e GEN 19 foram os que apresentaram frutos com maiores comprimentos (entre 14 e $15 \mathrm{~cm}$ ) e perímetros $(4 \mathrm{~cm})$. O número médio de frutos por penca foi 12,21 .

Segundo Donato et al. (2009), o comprimento e o perímetro do fruto são características importantes na classificação comercial da banana. O perímetro do fruto é normalmente usado para indicar o ponto de colheita. Frutos que não atingem o comprimento e o perímetro adequados são descartados na comercialização.

No primeiro ciclo, os genótipos GEN 6, GEN 9, GEN 10, GEN 11 e GEN 12 e GEN 23, que receberam nota 6 de severidade do mal-do-panamá (Tabela 3) produziram cachos (Tabela 5). Desses, no segundo ciclo, apenas o GEN 9, GEN 10 e o GEN 12 conseguiram produzir.

O genótipo GEN 19 destacou-se para massa das pencas, com 18,9 kg no primeiro ciclo e $21,9 \mathrm{~kg}$ no segundo ciclo (Tabelas 5 e 6), mesmo apresentando nota 3 de severidade do mal-do-panamá, em ambos os ciclos (Tabelas 3 e 4). Considerando cachos com $18,9 \mathrm{~kg}$ e a população de 1.960 plantas por hectare (utilizada neste ensaio), a estimativa de produtividade seria de $37.058 \mathrm{~kg} \mathrm{ha}^{-1}$ no primeiro ciclo.

Observam-se, na Tabela 6 , as médias dos componentes de produção do segundo ciclo de produção. Os genótipos apresentaram massa média do cacho de 13,36 kg, superando os valores obtidos no primeiro ciclo $(11,34 \mathrm{~kg})$. Donato et al. (2003, 2006), Rodrigues et al. (2006) e Ledo et al. (2008), ao trabalharem com esta característica, observaram incremento na produção, ao longo dos ciclos. Todavia, estes valores estão abaixo dos padrões relatados por Silva et al. (2008), Damato Júnior et al. (2005), Donato et al. (2006) e Donato et al. (2009).

O genótipo GEN 19 destacou-se novamente no segundo ciclo por apresentar maior massa de cacho, de $23 \mathrm{~kg}$ e de $21,9 \mathrm{~kg}$ sem o engaço. Esse genótipo ficou entre os que apresentaram o maior número de pencas (8), a segunda penca com maior número de frutos (14) e fruto central com as maiores dimensões (15 $\mathrm{cm}$ de comprimento e $4 \mathrm{~cm}$ de perímetro).

A massa média geral do engaço foi de 2,08 $\mathrm{kg}$, sendo que os genótipos GEN 3, GEN 9, GEN 10 e GEN 19 apresentaram menores valores $(1,1 \mathrm{~kg})$, e os genótipos GEN 2, GEN 7, GEN 12, GEN 13 e GEN 15, e GEN 18, os maiores valores (entre 2,4 e 3,1 kg). A massa média das pencas foi de 11,27 $\mathrm{kg}$, e os genótipos GEN 2 e GEN 19 apresentaram os maiores valores (21,9 e $14 \mathrm{~kg}$ ), e com menores valores, os genótipos GEN 12, GEN 13, GEN 15, GEN 18 e GEN 21 (entre 7,6 a 8,9 kg).

O número de pencas por cacho obteve média geral de 7,93, os genótipos GEN 18 e GEN 21, com menores médias ( 7 pencas) em relação aos demais genótipos que apresentaram 8 pencas. Oliveira et al. (2008) salientam a importância da característica número de pencas como fundamental para o melhoramento genético da bananeira, uma vez que a penca constitui-se na unidade comercial.

O genótipo GEN 19 apresentou a maior média do comprimento do fruto $(15 \mathrm{~cm})$, e o genótipo GEN 4 apresentou a menor média $(9 \mathrm{~cm})$, sendo a média geral de $11,93 \mathrm{~cm}$. Para perímetro do fruto, a média geral foi de 3,2 cm, sendo os genótipos GEN 1, GEN 2, GEN 4 e GEN 19 os que apresentaram as maiores médias $(4 \mathrm{~cm})$, e o genótipo GEN $21 \mathrm{com}$ menor perímetro $(2 \mathrm{~cm})$. A média geral de número de frutos por penca foi de 12,46, sendo que os genótipos GEN 2, GEN 15 e GEN 19 apresentaram as maiores médias (14 frutos), e os genótipos GEN 9 e GEN 11, as menores médias para esta característica (11 frutos).

Quanto aos valores médios de massa do cacho, os genótipos GEN 12 e GEN 13, com a nota de severidade 6, produziram cachos, bem como os genótipos GEN 1, GEN 2, GEN 7 e GEN 17 com nota de severidade 3 ou 4 . O genótipo GEN 2, embora com nota de severidade 3 , produziu massa de pencas de 15,6 kg. O genótipo GEN 13 produziu massa de penca de 14,9 $\mathrm{kg}$ com nota de severidade 5 . O genótipo GEN 17, mesmo com nota de severidade 3 , produziu massa de penca de $14,5 \mathrm{~kg}$. O genótipo GEN 1 produziu massa de penca de $14,0 \mathrm{~kg}$ com nota de severidade 2. Assim, pode ser observado que estes indivíduos apresentam uma possível tolerância à doença, pois mesmo sendo com altas notas de severidade da doença conseguiram produzir pencas de valor comercial e com peso acima de $14 \mathrm{~kg}$.

A seleção de genótipos de interesse (rendimento, qualidade, resistência ou tolerância a pragas e doenças) em plantios comerciais é muito importante na cultura da bananeira, tanto que as cultivares hoje utilizadas são resultantes deste tipo de seleção. Isto se deve à alta taxa de mutação observada, principalmente para alguns subgrupos, como o da Prata. É fundamental, entretanto, que sejam utilizadas ferramentas adequadas de verificação dos possíveis mutantes, uma vez que a expressão genotípica é altamente influenciada pelo ambiente, alterando o fenótipo. 
DIIJizmax

FICHA TÉCNICA - GLEBA C2

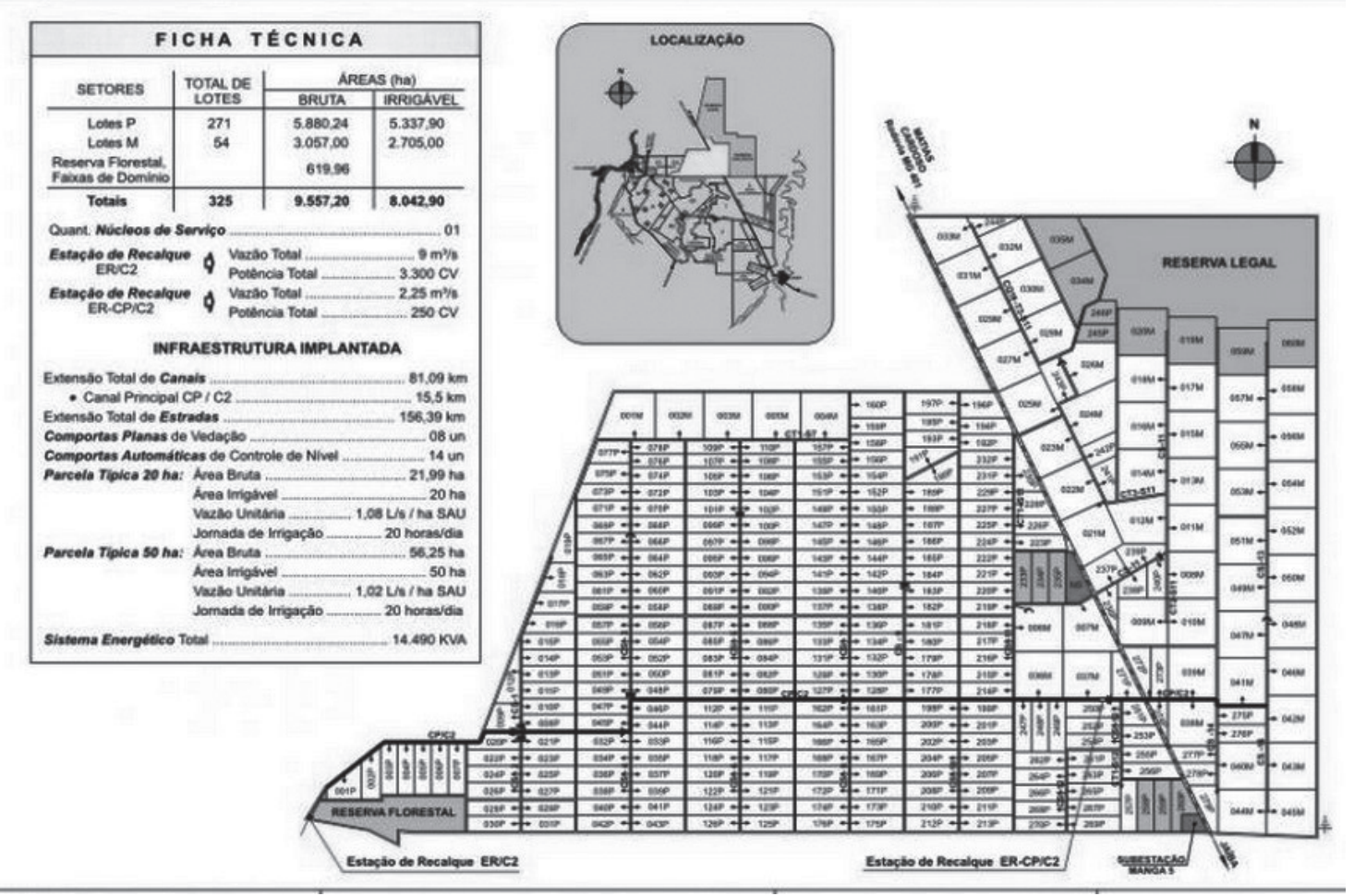

FIGURA 1- Gleba C2 do Projeto Jaíba: Ficha Técnica, Mapa do Perímetro e Mapa da Gleba.

TABELA 1 - Graus de severidade do mal-do-panamá de acordo com a escala do INIBAP (CHARLIER E ESCALANT, 2003) adaptada pelo autor.

Nota Descrição da escala de notas

1 Rizoma sem nenhum escurecimento

2 Pontos isolados de escurecimento no tecido vascular

3 Tecido vascular com até $1 / 3$ de escurecimento vascular

4 Tecido vascular apresentando entre $1 / 3$ a 2/3 de escurecimento vascular

5 Tecido vascular com mais de $2 / 3$ de escurecimento

6 Escurecimento total do tecido vascular

7* Escurecimento total do tecido vascular, rachaduras no pseudocaule, seca e quebra das folhas, Ausência de cacho, levando à morte a planta.

*Nota incluída para caracterização da presença de plantas com grau máximo de doença, observado no campo. 
TABELA 2 - Diâmetro do pseudocaule ao nível do solo (DPNS) e a $30 \mathrm{~cm}$ do solo (DP30) e altura de planta (AP) de genótipos de bananeira-'Prata-Anã' avaliados aos 270 dias após o plantio. Matias Cardoso-MG.

\begin{tabular}{lccc}
\hline GENÓTIPOS & AP $(\mathrm{cm})$ & DP30 $(\mathrm{cm})$ & DPNS $(\mathrm{cm})$ \\
\hline GEN 23 & $109,93 \mathrm{~A}$ & $23,77 \mathrm{~B}$ & $27,9 \mathrm{~B}$ \\
GEN 13 & $111,63 \mathrm{~A}$ & $27,19 \mathrm{~A}$ & $32,04 \mathrm{~A}$ \\
GEN 18 & $114,01 \mathrm{~A}$ & $27,08 \mathrm{~A}$ & $31,46 \mathrm{~A}$ \\
GEN 12 & $115,23 \mathrm{~A}$ & $27,18 \mathrm{~A}$ & $32,19 \mathrm{~A}$ \\
GEN 24 & $115,54 \mathrm{~A}$ & $24,83 \mathrm{~B}$ & $29,3 \mathrm{~B}$ \\
GEN 22 & $117,73 \mathrm{~A}$ & $28,71 \mathrm{~A}$ & $34,03 \mathrm{~A}$ \\
GEN 19 & $120,69 \mathrm{~A}$ & $28,16 \mathrm{~A}$ & $33,74 \mathrm{~A}$ \\
GEN 1 & $121,07 \mathrm{~A}$ & $25,81 \mathrm{~B}$ & $29,35 \mathrm{~B}$ \\
GEN 4 & $91,7 \mathrm{~B}$ & $21,17 \mathrm{~B}$ & $26,43 \mathrm{~B}$ \\
GEN 2 & $96,22 \mathrm{~B}$ & $23,82 \mathrm{~B}$ & $31,73 \mathrm{~A}$ \\
GEN 7 & $97,56 \mathrm{~B}$ & $22,06 \mathrm{~B}$ & $26,8 \mathrm{~B}$ \\
GEN 5 & $99,1 \mathrm{~B}$ & $22,12 \mathrm{~B}$ & $26,52 \mathrm{~B}$ \\
GEN 16 & $100,34 \mathrm{~B}$ & $23,99 \mathrm{~B}$ & $29,33 \mathrm{~B}$ \\
GEN 9 & $101,39 \mathrm{~B}$ & $23,79 \mathrm{~B}$ & $28,43 \mathrm{~B}$ \\
GEN 21 & $102,18 \mathrm{~B}$ & $24,87 \mathrm{~B}$ & $29,61 \mathrm{~B}$ \\
GEN 8 & $103,69 \mathrm{~B}$ & $24,37 \mathrm{~B}$ & $29,18 \mathrm{~B}$ \\
GEN 14 & $103,7 \mathrm{~B}$ & $24,82 \mathrm{~B}$ & $29,48 \mathrm{~B}$ \\
GEN 15 & $103,7 \mathrm{~B}$ & $24,38 \mathrm{~B}$ & $29,15 \mathrm{~B}$ \\
GEN 6 & $103,08 \mathrm{~B}$ & $24,88 \mathrm{~B}$ & $30,52 \mathrm{~A}$ \\
GEN 10 & $103,9 \mathrm{~B}$ & $25,29 \mathrm{~B}$ & $29,83 \mathrm{~B}$ \\
GEN 3 & $105,61 \mathrm{~B}$ & $25,63 \mathrm{~B}$ & $30,53 \mathrm{~A}$ \\
GEN 20 & $106,44 \mathrm{~B}$ & $24,87 \mathrm{~B}$ & $29,83 \mathrm{~B}$ \\
GEN 11 & $106,67 \mathrm{~B}$ & $25,08 \mathrm{~B}$ & $30,63 \mathrm{~A}$ \\
GEN 17 & $107,18 \mathrm{~B}$ & $24,31 \mathrm{~B}$ & $28,43 \mathrm{~B}$ \\
Média & 106,60 & 24,92 & 29,85 \\
CV\% & 18,4 & $15,9 \%$ & $17,9 \%$ \\
\hline & & &
\end{tabular}

*Médias seguidas pelas mesmas letras na coluna pertencem ao mesmo grupo, pelo teste de Scott Knott, a $5 \%$ de probabilidade. 
TABELA 3 - Porcentagem de plantas mortas, incidência e severidade do mal-do-panamá em genótipos de bananeira-'Prata-Anã' no primeiro ciclo de produção. Matias Cardoso-MG.

\begin{tabular}{cccc}
\hline GENÓTIPOS & Plantas Mortas (\%) & Incidência & Severidade \\
\hline GEN 1 & $88,88 \pm 9,62$ & $100 \pm 0,0$ & $4,66 \pm 2,08$ \\
GEN 2 & $100 \pm 0,0$ & $100 \pm 0,0$ & $7,00 \pm 0,00$ \\
GEN 3 & $100 \pm 0,0$ & $100 \pm 0,0$ & $7,00 \pm 0,00$ \\
GEN 4 & $100 \pm 0,0$ & $100 \pm 0,0$ & $7,00 \pm 0,00$ \\
GEN 5 & $88,88 \pm 19,24$ & $100 \pm 0,0$ & $5,66 \pm 2,30$ \\
GEN 6 & $94,44 \pm 9,62$ & $100 \pm 0,0$ & $6,66 \pm 0,57$ \\
GEN 7 & $66,66 \pm 16,66$ & $84,66 \pm 2,88$ & $2,66 \pm 0,57$ \\
GEN 8 & $100 \pm 0,0$ & $100 \pm 0,0$ & $7,00 \pm 0,00$ \\
GEN 9 & $88,88 \pm 19,24$ & $100 \pm 0,0$ & $6,33 \pm 0,00$ \\
GEN 10 & $96,29 \pm 6,42$ & $100 \pm 0,0$ & $6,00 \pm 1,73$ \\
GEN 11 & $87,03 \pm 6,41$ & $100 \pm 0,0$ & $6,66 \pm 0,57$ \\
GEN 12 & $94,44 \pm 9,62$ & $100 \pm 0,0$ & $6,33 \pm 1,15$ \\
GEN 13 & $92,59 \pm 8,48$ & $100 \pm 0,0$ & $4,33 \pm 2,51$ \\
GEN 14 & $88,88 \pm 09,62$ & $100 \pm 0,0$ & $4,66 \pm 2,08$ \\
GEN 15 & $77,77 \pm 25,45$ & $94 \pm 0$ & $3,66 \pm 2,88$ \\
GEN 16 & $88,88 \pm 9,62$ & $100 \pm 0,0$ & $5,00 \pm 1,73$ \\
GEN 17 & $83,33 \pm 0,0$ & $100 \pm 0,0$ & $3,33 \pm 0,57$ \\
GEN 18 & $72,22 \pm 34,69$ & $83 \pm 0$ & $4,33 \pm 2,51$ \\
GEN 19 & $94,44 \pm 09,62$ & $100 \pm 0,0$ & $3,00 \pm 2,30$ \\
GEN 20 & $94,44 \pm 9,62$ & $100 \pm 0,0$ & $5,66 \pm 2,30$ \\
GEN 21 & $77,77 \pm 19,24$ & $86,33 \pm 2,88$ & $5,00 \pm 1,73$ \\
GEN 22 & $100 \pm 0,0$ & $100 \pm 0,0$ & $7,00 \pm 0,00$ \\
GEN 23 & $94,44 \pm 9,62$ & $100 \pm 0,0$ & $6,00 \pm 1,73$ \\
GEN 24 & $100 \pm 0,0$ & $100 \pm 0,0$ & $7,00 \pm 0,00$ \\
\hline
\end{tabular}


TABELA 4 - Porcentagem de plantas mortas (PM), incidência e severidade do mal-do-panamá de genótipos de bananeira-'Prata-Anã' no segundo ciclo de produção. Matias Cardoso-MG.

\begin{tabular}{cccc}
\hline GENÓTIPOS & PM $(\%)$ & Incidência & Severidade \\
\hline GEN 1 & $72,21 \pm 9,62$ & $100 \pm 0,0$ & $3,33 \pm 1,15$ \\
GEN 2 & $77,77 \pm 9,62$ & $100 \pm 0,0$ & $3,00 \pm 1,00$ \\
GEN 3 & $94,44 \pm 9,62$ & $100 \pm 0,0$ & $5,33 \pm 2,88$ \\
GEN 4 & $94,44 \pm 9,62$ & $100 \pm 0,0$ & $5,66 \pm 2,30$ \\
GEN 5 & $100 \pm 0,0$ & $100 \pm 0,0$ & $7,00 \pm 0,00$ \\
GEN 6 & $100 \pm 0,0$ & $100 \pm 0,0$ & $7,00 \pm 0,00$ \\
GEN 7 & $72,22 \pm 25,45$ & $100 \pm 0,0$ & $3,66 \pm 2,88$ \\
GEN 8 & $100 \pm 0,0$ & $100 \pm 0,0$ & $7,00 \pm 0,00$ \\
GEN 9 & $100 \pm 0,0$ & $100 \pm 0,0$ & $7,00 \pm 0,00$ \\
GEN 10 & $88,88 \pm 19,24$ & $100 \pm 0,0$ & $6,00 \pm 1,73$ \\
GEN 11 & $100 \pm 0,0$ & $100 \pm 0,0$ & $7,00 \pm 0,00$ \\
GEN 12 & $94,44 \pm 9,62$ & $100 \pm 0,0$ & $6,33 \pm 1,15$ \\
GEN 13 & $83,33 \pm 16,67$ & $100 \pm 0,0$ & $6,00 \pm 1,00$ \\
GEN 14 & $100 \pm 0,0$ & $100 \pm 0,0$ & $7,00 \pm 0,00$ \\
GEN 15 & $94,44 \pm 9,62$ & $100 \pm 0,0$ & $5,33 \pm 2,88$ \\
GEN 16 & $100 \pm 0,0$ & $100 \pm 0,0$ & $7,00 \pm 0,00$ \\
GEN 17 & $77,77 \pm 19,24$ & $100 \pm 0,0$ & $4,33 \pm 2,51$ \\
GEN 18 & $55,55 \pm 19,24$ & $100 \pm 0,0$ & $2,33 \pm 0,57$ \\
GEN 19 & $94,44 \pm 9,62$ & $100 \pm 0,0$ & $3,33 \pm 1,15$ \\
GEN 20 & $100 \pm 0,0$ & $100 \pm 0,0$ & $7,00 \pm 0,00$ \\
GEN 21 & $83,33 \pm 16,67$ & $100 \pm 0,0$ & $5,00 \pm 2,00$ \\
GEN 22 & $100 \pm 0,0$ & $100 \pm 0,0$ & $7,00 \pm 0,0$ \\
GEN 23 & $100 \pm 0,0$ & $100 \pm 0,0$ & $7,00 \pm 0,0$ \\
GEN 24 & $100 \pm 0,0$ & $100 \pm 0,0$ & $7,00 \pm 0,0$ \\
\hline & & & \\
\hline
\end{tabular}


TABELA 5 - Número de plantas avaliadas (N), massa do cacho (MC), do engaço (ME) e das pencas (PP), número de pencas $(\mathrm{NP})$; comprimento $(\mathrm{CF})$ e perímetro do fruto central $(\mathrm{PF})$ e número de frutos por penca (NFP), do $1^{\circ}$ Ciclo de produção de genótipos de bananeira-'Prata-Anã'. Matias Cardoso-MG.

\begin{tabular}{ccccccccc}
\hline Genótipo & $\mathrm{N}$ & $\mathrm{MC}(\mathrm{Kg})$ & $\mathrm{ME}(\mathrm{Kg})$ & $\mathrm{MP}(\mathrm{Kg})$ & $\mathrm{NP}$ & $\mathrm{CF}(\mathrm{cm})$ & $\mathrm{PF}(\mathrm{cm})$ & $\mathrm{NFP}$ \\
\hline GEN 1 & 2 & $13,9 \pm 0,49$ & $2,2 \pm 0,14$ & $11,7 \pm 0,63$ & $8 \pm 0$ & $14 \pm 0,71$ & $4 \pm 0,28$ & $14 \pm 0$ \\
GEN 5 & 2 & $11,5 \pm 1,06$ & $1 \pm 0$ & $10,5 \pm 1,06$ & $7 \pm 0,71$ & $14 \pm 0,71$ & $4 \pm 0,28$ & $14 \pm 0,71$ \\
GEN 6 & 1 & 11,3 & 0,8 & 10,5 & 8 & 13 & 3 & 13 \\
GEN 7 & 6 & $9,7 \pm 4,80$ & $2,7 \pm 0,98$ & $7 \pm 4,60$ & $7 \pm 1,21$ & $11 \pm 2,61$ & $3 \pm 1,08$ & $11 \pm 2,79$ \\
GEN 9 & 2 & $12,1 \pm 2,05$ & $2,1 \pm 1,27$ & $10 \pm 0,77$ & $9 \pm 0,71$ & $12 \pm 0$ & $3 \pm 0$ & $11 \pm 0$ \\
GEN 10 & 1 & 11,5 & 1,1 & 10,4 & 8 & 12 & 3 & 12 \\
GEN 11 & 2 & $12,4 \pm 1,20$ & $1 \pm 0$ & $11,4 \pm 1,20$ & $8 \pm 0$ & $11 \pm 0,71$ & $3 \pm 0$ & $13 \pm 1,41$ \\
GEN 12 & 1 & 8,6 & 2,5 & 6,1 & 8 & 9 & 2 & 13 \\
GEN 13 & 2 & $14 \pm 7$ & $2,8 \pm 0,21$ & $11,2 \pm 6,78$ & $8 \pm 0,71$ & $10 \pm 2,73$ & $3 \pm 1,41$ & $13 \pm 0,71$ \\
GEN 14 & 2 & $7,6 \pm 1,91$ & $1,2 \pm 0,49$ & $6,4 \pm 2,40$ & $8 \pm 0,71$ & $10 \pm 1,41$ & $2 \pm 0$ & $12 \pm 2,12$ \\
GEN 15 & 4 & $11,1 \pm 3,87$ & $2,4 \pm 0,88$ & $8,7 \pm 3,55$ & $8 \pm 1,73$ & $12 \pm 2,38$ & $3 \pm 0,39$ & $12 \pm 2,22$ \\
GEN 16 & 2 & $11,1 \pm 5,02$ & $2,7 \pm 0,99$ & $8,4 \pm 6,01$ & $8 \pm 0$ & $9 \pm 0,71$ & $3 \pm 1,20$ & $11 \pm 1,41$ \\
GEN 17 & 3 & $10,6 \pm 5,18$ & $1,8 \pm 0,31$ & $8,8 \pm 4,88$ & $8 \pm 0,58$ & $11 \pm 1,73$ & $3 \pm 0,40$ & $12 \pm 1,53$ \\
GEN 18 & 5 & $9,2 \pm 2,70$ & $2,2 \pm 0,95$ & $7 \pm 1,83$ & $8 \pm 0,55$ & $12 \pm 1,79$ & $3 \pm 0,87$ & $12 \pm 2$ \\
GEN 19 & 1 & 20 & 1,1 & 18,9 & 8 & 15 & 4 & 14 \\
GEN 20 & 1 & 9,3 & 2,8 & 6,5 & 8 & 9 & 2 & 9 \\
GEN 21 & 4 & $9,7 \pm 4,82$ & $2,4 \pm 1,03$ & $7,3 \pm 4,83$ & $7 \pm 0,5$ & $10 \pm 1,70$ & $3 \pm 0,64$ & $12 \pm 1,26$ \\
GEN 23 & 1 & 12,4 & 2,1 & 10,3 & 8 & 12 & 4 & 12 \\
\hline Médias & & 11,34 & 1,97 & 9,51 & 7,89 & 11,47 & 3,05 & 12,21 \\
\hline
\end{tabular}

TABELA 6 - Número de plantas avaliadas (N), massa do cacho (MC), do engaço (ME) e das pencas (MP), número de pencas $(\mathrm{NP})$, comprimento $(\mathrm{CF})$ e perímetro do fruto central $(\mathrm{PF})$ e número de frutos por penca (NFP), do $2^{\circ}$ Ciclo de produção de genótipos de bananeira-'Prata-Anã'. Matias Cardoso-MG.

\begin{tabular}{ccccccccc}
\hline Genótipo & $\mathrm{N}$ & $\mathrm{MC}(\mathrm{Kg})$ & $\mathrm{ME}(\mathrm{Kg})$ & $\mathrm{MP}(\mathrm{Kg})$ & $\mathrm{NP}$ & $\mathrm{CF}(\mathrm{cm})$ & $\mathrm{PF}(\mathrm{cm})$ & $\mathrm{NFP}$ \\
\hline GEN 1 & 4 & $14,9 \pm 1,17$ & $2,1 \pm 0,20$ & $12,8 \pm 0,88$ & $8 \pm 0,5$ & $13 \pm 0,81$ & $4 \pm 0,47$ & $13 \pm 1$ \\
GEN 2 & 4 & $16,6 \pm 1,61$ & $2,5 \pm 0,66$ & $14,1 \pm 1,90$ & $8 \pm 0$ & $13 \pm 0,95$ & $4 \pm 0,5$ & $14 \pm 0.57$ \\
GEN 3 & 1 & 11,5 & 1,1 & 10,4 & 8 & 12 & 3 & 12 \\
GEN 4 & 1 & 14 & 2 & 12 & 8 & 9 & 4 & 12 \\
GEN 7 & 6 & $13,5 \pm 1,91$ & $2,7 \pm 0,91$ & $10,8 \pm 2,36$ & $8 \pm 0,57$ & $12 \pm 1,73$ & $3 \pm 0,95$ & $13 \pm 1,29$ \\
GEN 9 & 1 & 14,2 & 1,2 & 13 & 8 & 12 & 3 & 11 \\
GEN 10 & 2 & $13,3 \pm 1,76$ & $1,1 \pm 0$ & $12,2 \pm 1,76$ & $8 \pm 0$ & $11 \pm 0,70$ & $3 \pm 0$ & $12 \pm 1,41$ \\
GEN 12 & 1 & 10,6 & 2,9 & 7,7 & 8 & 12 & 3 & 13 \\
GEN 13 & 3 & $11,2 \pm 1,58$ & $2,4 \pm 0,57$ & $8,8 \pm 1,01$ & $8 \pm 0$ & $12 \pm 1,52$ & $3 \pm 1,58$ & $12 \pm 0,57$ \\
GEN 15 & 1 & 12 & 3,1 & 8,9 & 9 & 13 & 3 & 14 \\
GEN 17 & 4 & $11,6 \pm 3,94$ & $1,9 \pm 0,3$ & $9,7 \pm 3,67$ & $8 \pm 0,5$ & $11 \pm 1,5$ & $3 \pm 0,78$ & $12 \pm 1,41$ \\
GEN 18 & 6 & $11,2 \pm 2,94$ & $2,7 \pm 0,84$ & $8,5 \pm 2,39$ & $7 \pm 0,35$ & $12 \pm 1,16$ & $3 \pm 0,68$ & $12 \pm 1,66$ \\
GEN 19 & 1 & 23 & 1,1 & 21,9 & 8 & 15 & 4 & 14 \\
GEN 21 & 3 & $9,7 \pm 5,96$ & $2,1 \pm 0,90$ & $7,6 \pm 5,41$ & $7 \pm 0,57$ & $10 \pm 2$ & $2 \pm 0,69$ & $11 \pm 1,52$ \\
\hline Médias & 13,36 & 2,09 & 11,27 & 7,93 & 11,93 & 3,20 & 12,47 \\
\hline
\end{tabular}




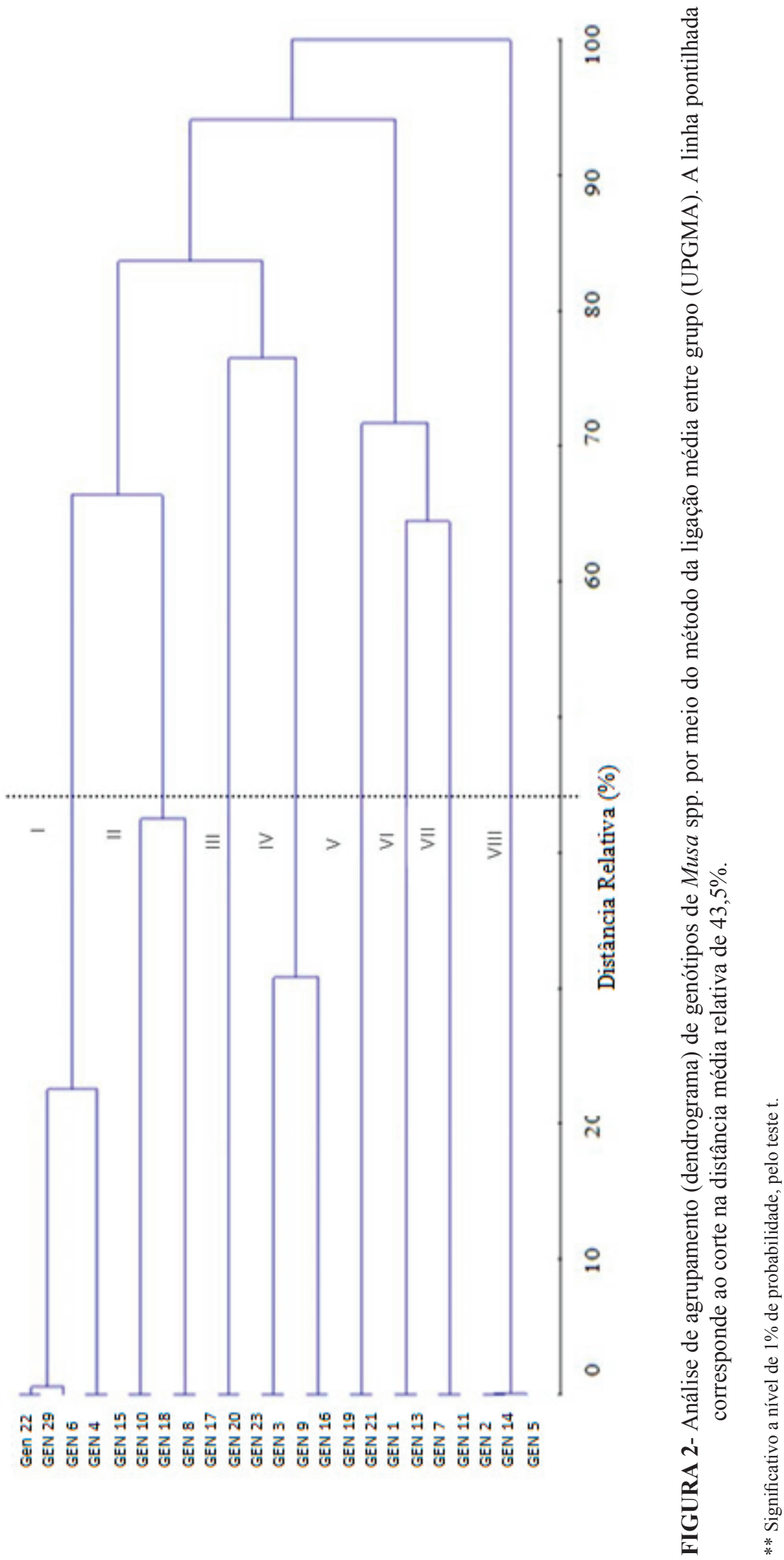



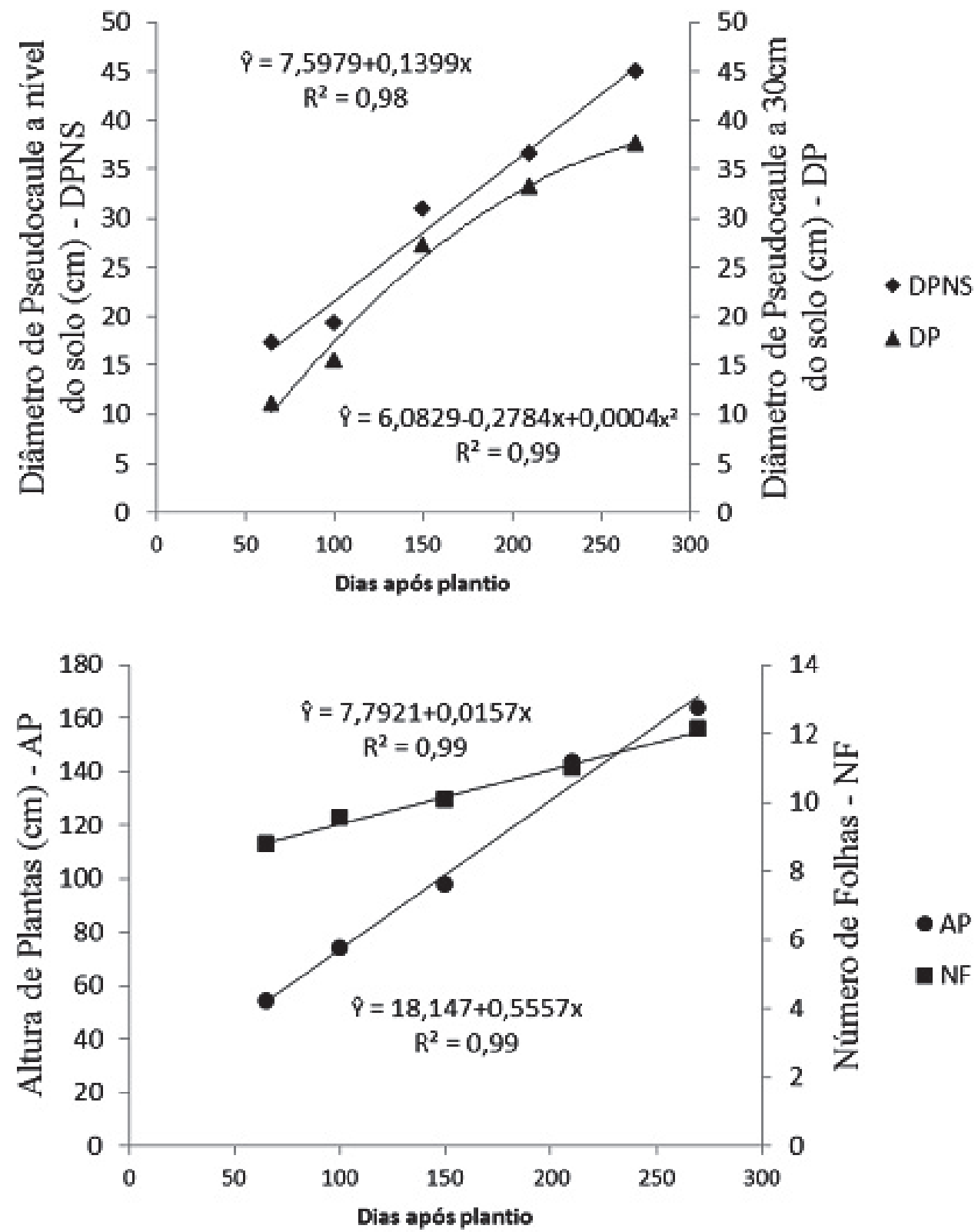

FIGURA 3 - Diâmetro do pseudocaule ao nível do solo, diâmetro do pseudocaule a $30 \mathrm{~cm}$, altura das plantas e número de folhas de bananeira-'Prata-Anã' em função dos dias após o plantio. Matias Cardoso-MG. 


\section{CONCLUSÕES}

Não é observada correlação entre a severidade ao mal-do-panamá e os componentes de produção.

Os genótipos de bananeira 'Prata-Anã' em estudo são variantes somaclonais.

Os genótipos GEN 13, GEN 17 e GEN 19 produzem bem nos dois primeiros ciclos, mesmo manifestando sintomas do mal-do-panamá.

Os genótipos GEN 12, GEN 13, GEN 19 e GEN 22 possuem maiores diâmetros do pseudocaule ao nível do solo e a $30 \mathrm{~cm}$ do solo, e são mais altos.

\section{AGRADECIMENTOS}

À Fazenda Luiz Schwartz, à Fundação de Amparo a Pesquisa do Estado de Minas Gerais (Fapemig), ao Conselho Nacional de Desenvolvimento Científico e Tecnológico (CNPq) e à Coordenadoria de Aperfeiçoamento de Pessoal de Nível Superior (Capes), pelo apoio financeiro e pela concessão de bolsas.

\section{REFERÊNCIAS}

ARANTES, A.M.; DONATO, S.R.L.; SILVA, S de O. e. Relação entre características morfológicas e componentes de produção em plátanos. Pesquisa Agropecuária Brasileira, Brasília, v.45, p.224227, 2010.

CHARLIER, J.; WAELE, D. de; ESCALANT, J. Global evaluation of Musa germplasm for resistance to Fusarium wilt, Mycosphaerella leaf spotdiseases and nematodes. INIBAP Technical Guidelines, Montpellier, v.7, p.27- 62, 2003.

CORDEIRO, Z.J.M.; MATOS, A. P.; KIMATI, H. DOENÇAS DA BANANEIRA. IN: KIMATI, H.; AMORIM, L.; REZENDE, J.A.M. BERGAMIN FILHO, A.; CAMARGO, L.E.A.; (Ed.). Manual de fitopatologia:. São Paulo: Agronômica Ceres, 2005.v. 2, p. 99-117.

CORDEIRO, Z. J. M.; MATOS A. P. de; MEISSNER FILHO, P. E. Doenças e métodos de controle. In: BORGES, A. L.; SOUZA, L. da S. O cultivo da bananeira. Cruz das Almas: Embrapa Mandioca e Fruticultura Tropical, 2004. cap. 9, p. 146 - 182.
CRUZ, C. D. GENES - versão Windows. Viçosa: Editora ufv, 2006. 642 p.

DAMATTO JUNIOR, E. R.; CAMPOS, A. J. de; MANOEL, L.; MOREIRA, G. C.; LEONE, S.; EVANGELISTA, R. M. Produção e caracterização de frutos de bananeira 'Prata-Anã'e 'Prata-Zulu'. Revista Brasileira de Fruticultura, v.27, n.3, p. 440-443, 2005.

DONATO, S.L.R.; SILVA, S. de O. e; PASSOS, A.R.; LIMA NETO, F.P.; LIMA, M.B. Avaliação de variedades e híbridos de bananeira sob irrigação. Revista Brasileira de Fruticultura, Jaboticabal, v.25, n.2, p.348-351, ago, 2003.

DONATO, S.L.R.; ARANTES, A. de M.; SILVA, S. de O. e; CORDEIRO, Z.J.M. Comportamento fitotécnico da bananeira 'Prata-Anã' e de seus híbridos. Pesquisa Agropecuária Brasileira, Brasília v.44, p.1608-1615, 2009.

DONATO, S. L. R.; SILVA, S. O.; LUCCA FILHO, O. A.; LIMA, M. B.; DOMINGUES, H.; ALVES, J.

S. Correlação entre caracteres da planta e do cacho em bananeira (Musa spp). Ciência e Agrotecnologia, Lavras, v. 30, n. 1, p. 21-30, jan./fev. 2006

DOYLE, J. J.; DOYLE, J. L. Isolation of plant DNA from fresh tissue. Focus, Rockville, v.12, p.13-15, 1990 .

FERREIRA， M.E.; GRATTAPA GLIA, $D$. Introdução ao uso de marcadores moleculares em análise genética. 2.ed. Brasília: EMBRAPACENARGEN, 1996. 220p.

GOMES, A. M. Avaliação da supressão do mal-dopanamá em uma área de banana no Projeto Jaíba. 2010. 32 f. Monografia (Trabalho de Graduação em Agronomia) - Universidade Estadual de Montes Claros, Janaúba, 2010.

GONÇALVES, V.D.; NIETSCHE, S.; PEREIRA, M.C.T.; SILVA, S.O.; SANTOS, T.M.; OLIVEIRA, J.R.; FRANCO, L.R.L.; RUGGIERO, C. Avaliação das cultivares de bananeira Prata-Anã, Thap Maeo e Caipira em diferentes sistemas de plantio no Norte de Minas Gerais. Revista Brasileira de Fruticultura, Jaboticabal, v.30, n.2, p.371-376, jun. 2008. 
GUBBUK, H; PEKMEZCI, M; ONUS, N. A; ERKAN, M. Identification and selection of superior banana phenotypes in the cultoivar Dwarf Cavendish using agronomic characteristics and RAPD markers. Pakistan Journal of Botany, Islamabad, v.36, n.2, p.331-342, 2004.

GUIMARÃES, B.V.C.; DONATO, S.L.R.; MAIA, V.M.; ASPIAZÚ, I.; COELHO, E.F. Phenotypical correlations between agronomical characters in Prata type bananas (Musa) and its implications on yield estimate. African Journal of Agricultural Research, Lagos, v. 9, n. 17, p. 1358-1365, 2014.

LÉDO, A.S.; SILVA JÚNIOR, J.F.; LÉDO, C.A.S.; SILVA, S.O. Avaliação de genótipos de bananeira na região do Baixo São Francisco, Sergipe. Revista Brasileira de Fruticultura, Jaboticabal, v.30, n.3, p.691-695, set. 2008.

LIBRELON, S.S; COSTA, M. R; NIETSCHE, S; PEREIRA, M. C. T. Diversidade genética de clones de bananeira 'Prata-anã' (aab) por meio de marcadores SSR. Revista Brasileira de Fruticultura, Jaboticabal, v. 35, n. 3, p. 809-817, 2013.

MARQUES, P. R. R.; DONATO, S.L.R.; PEREIRA, M. C. T.; COELHO, E. F.; ARANTES, A. de M. Características Agronômicas de bananeiras tipo Prata sob diferentes sistemas de irrigação. Pesquisa Agropecuária Brasileira, Brasília, v.46, n.8, p.852859, 2011.

MENDONÇA, K.H; DUARTE, D. A. S; COSTA, V. A. M; MATOS, G. R; SELEGUINI, A. Avaliação de genótipos de bananeira em Goiânia, Estado de Goiás. Revista Ciência Agronômica, Fortaleza, v. 44, n. 3, p. 652-660, 2013.

MICHEREFF, S. J.; ANDRADE, D. E. G. T.; PERUCH, L. A. M. Inóculo de patógenos radiculares. In: MICHEREFF, S. J. Ecologia e manejo de patógenos radiculares em solos tropicais. Recife: UFRPE, Imprensa Universitária, 2005. cap. 5, p. 93-124.
OLIVEIRA, T. K.; LESSA, L. S.; SILVA, S. O.; OLIVEIRA, J. P. Características agronômicas de genótipos de bananeira em três ciclos de produção em Rio Branco-AC. Pesquisa Agropecuária Brasileira, Brasília, v.43, n.8, p.1003-1010, 2008.

RAHMAN, M. M.; BALA, B. K. Modelling of jute production using artificial neural networks. Biosystems Engineering, London, v. 105, n. 3, p. 350-356, 2010.

RODRIGUES, F. E.; LIBRELON, S.S.; NIETSCHE, S.; COSTA, M.R.; PEREIRA, M.C.T. Genetic variability in clones of 'Prata Anã' bananas based on phenotypic and molecular markers. Bragantia, Campinas, v.72. n.2, p.182-189 2012.

RODRIGUES, M. G. V.; SOUTO, R. F.; SILVA, S. de $\mathrm{O}$. Avaliação de genótipos de bananeira sob irrigação. Revista Brasileira de Fruticultura, Jaboticabal, v. 28, n. 3, p. 444-448, 2006.

SILVA, S. de O. e; FLORES, J. C. de O.; LIMA NETO, F. P. Avaliação de variedades e híbridos de bananeira em quatro ciclos de produção. Pesquisa Agropecuária Brasileira, Brasília, v.37, n.1, p.15671574, 2002.

SILVA, S.O.; PEREIRA, L.V.; RODRIGUES, M.G.V. Bananicultura irrigada: inovações tecnológicas: variedades. Informe Agropecuário, Belo Horizonte, v.29, n.245, p.78-83, jul./ago. 2008.

UFV. SAEG - Sistema de análises estatísticas e genética (Versão 5.0). Viçosa: Universidade Federal de Viçosa, 1997.

VENTURA, J. A.; HINZ, R. H. Controle das doenças da bananeira. In: ZAMBOLIM, L. et al. (Ed.). Controle de doenças de plantas: fruteiras. Viçosa: UFV, 2002. v. 2, cap. 14, p. 839-906.

VISSER, A. A. Characterization of banana and plantain using random amplified polymorphic DNA markers. Acta Horticulturae, The Hague, v.540, p.113-123, 2000. 